\title{
Hypertrophic differentiation of mesenchymal stem cells is suppressed by xanthotoxin via the p38-MAPK/HDAC4 pathway
}

\author{
ZHEN CAO $^{1,2}$, YUN BAI $^{2}$, CHUAN LIU $^{2}$, CE DOU $^{2}$, JIANMEI LI $^{2}$, JUNYU XIANG $^{2}$, CHUNRONG ZHAO $^{2}$, \\ ZHAO XIE ${ }^{3}$, QIANG XIANG ${ }^{4}$ and SHIWU DONG ${ }^{2}$ \\ Departments of ${ }^{1}$ Anatomy and ${ }^{2}$ Biomedical Materials Science, School of Biomedical Engineering, \\ Third Military Medical University; Departments of ${ }^{3}$ Orthopedics and ${ }^{4}$ Emergency, Southwest \\ Hospital, Third Military Medical University, Chongqing 400038, P.R. China
}

Received November 19, 2016; Accepted June 8, 2017

DOI: $10.3892 / \mathrm{mmr} .2017 .6886$

\begin{abstract}
Chondrocyte hypertrophy is a physiological process in endochondral ossification. However, the hypertrophic-like alterations of chondrocytes at the articular surface may result in osteoarthritis $(\mathrm{OA})$. In addition, the generation of fibrocartilage with a decreased biological function in tissue engineered cartilage, has been attributed to chondrocyte hypertrophy. Therefore, suppressing chondrocyte hypertrophy in OA and the associated regeneration of non-active cartilage is of primary concern. The present study examined the effects of xanthotoxin (XAT), which is classified as a furanocoumarin, on chondrocyte hypertrophic differentiation of mesenchymal stem cells. Following XAT treatment, the expression levels of genes associated with chondrocyte hypertrophy were detected via immunohistochemistry, western blotting and reverse transcription-quantitative polymerase chain reaction. The results revealed that XAT inhibited the expression of various chondrocyte hypertrophic markers, including runt related transcription factor 2 (Runx2), matrix metalloproteinase 13 and collagen type $\mathrm{X} \alpha 1$ chain. Further exploration indicated that XAT reduced the activation of p38-mitogen activated protein kinase and then increased the expression of histone deacetylase 4 to suppress Runx2. The findings indicated that XAT maintained the chondrocyte phenotype in regenerated cartilage and therefore may exhibit promise as a potential drug for the treatment of OA in the future.
\end{abstract}

Correspondence to: Professor Shiwu Dong, Department of Biomedical Materials Science, School of Biomedical Engineering, Third Military Medical University, 30 Gaotanyan Street, Chongqing 400038, P.R. China

E-mail: dongshiwu@tmmu.edu.cn

Key words: xanthotoxin, mesenchymal stem cell, chondrocyte hypertrophy, MAPK, HDAC4

\section{Introduction}

Chondrocyte hypertrophic differentiation is a physiological stage in endochondral ossification which starts from the condensation of mesenchymal stem cells (MSCs) (1). Then MSCs which are located within the centre of condensation differentiate to chondrocytes (2). After proliferation, chondrocytes present hypertrophic morphology and secrete metal matrix proteinase to facilitate angiopoiesis and the formation of bone collar (3). However, the pathogenesis of osteoarthritis $(\mathrm{OA})$ is that hyaline cartilages situated in the surface of osteoarticular manifest unbalanced homeostasis and chondrocytes differentiate into hypertrophy $(4,5)$. Additionally, utilizing tissue engineering to repair cartilage defects, the regenerated cartilages are fibrocartilages and the chondrocytes from MSCs express hypertrophic marker protein (6,7). Thus it can be seen that inhibition of pathological chondrocyte hypertrophy is a very important proposition.

Xanthotoxin (XAT) is mainly isolated in plants such as Umbelliferae and Rutaceae which are used for the treatment of vitiligo, psoriasis and other skin diseases $(8,9)$. Besides, XAT can also induce apoptosis of tumor cells $(10,11)$. It was demonstrated that XAT had anticonvulsant pharmacological effects in the maximal electroshock-induced seizure test (12). However, the effect of XAT on chondrocyte differentiation remains unclear. Therefore, the purpose of this study is to investigate the effect of XAT on chondrocyte hypertrophy of MSCs.

Here, we set out to explore whether XAT could inhibit hypertrophic differentiation of MSCs. Furthermore, we also screened the upstream transcription factors of Runx2, a marker of chondrocyte hypertrophy, to find the molecular mechanism involved in the effect of XAT on chondrocyte hypertrophy.

\section{Materials and methods}

Reagents and cell culture. XAT (catalog no. M3501) was purchased from Sigma (St. Louis, MO, USA) which was dissolved in DMSO. Besides, the experimental concentration of DMSO is $0.1 \%$ and the control groups were given a DMSO vehicle treatment. C3H10T1/2 mesenchymal stem cells were 
Table I. Primer sequences for qPCR.

\begin{tabular}{llll}
\hline Genes & \multicolumn{1}{c}{ Forward $\left(5^{\prime}-3^{\prime}\right)$} & \multicolumn{1}{c}{ Reverse $\left(5^{\prime}-3^{\prime}\right)$} & Tm $\left({ }^{\circ} \mathrm{C}\right)$ \\
\hline HDAC4 & CACTCCTCTACGGCACAAATCC & CCAACACCACCACAAGGAAGC & 60 \\
Sox9 & CCCAGCGAACGCACATCA & TGGTCAGCGTAGTCGTATT & 61 \\
Col2a1 & TGGTGGAGCAGCAAGAGC & TGGACAGTAGACGGAGGAAA & 60 \\
GAPDH & GTTGTCTCCTGCGACTTCA & GGTGGTCCAGGGTTTCTTA & 62 \\
Col10a1 & CTTTCTGGGATGCCGCTTGT & GGGTCGTAATGCTGCTGCCTA & 61 \\
Runx2 & CCAACTTCCTGTGCTCCGTG & ATAACAGCGGAGGCATTTCG & 63 \\
Mmp13 & TTGATGCCATTACCAGTCTCCG & CACGGGATGGATGTTCATATGC & 61 \\
\hline
\end{tabular}

purchased from the American Type Culture Collection (ATCC; Manassas, VA, USA). The cells were cultured in DMEM-F12 containing 10\% fetal bovine serum (FBS) (both from Hyclone, Logan, UT, USA) and $1 \%$ penicillin-streptomycin solution (Beyotime, Shanghai, China) at $37^{\circ} \mathrm{C}$ with $5 \%$ $\mathrm{CO}_{2}$. The culture medium was replaced every 2-3 d until the cells reached $90 \%$ confluence. Cells were passaged by $0.25 \%$ trypsin (Hyclone) for $2 \mathrm{~min}$ at room temperature. The second generation cells were used for the following experiments.

In vitro cell proliferation assay. C3H10T1/2 cells were seeded $\left(2 \times 10^{3} /\right.$ well) into 96 -well plates (Corning, Corning, NY, USA) in triplicates and allowed to adhere overnight. On the following day, the medium was replaced by fresh medium with different concentrations of XAT $(10,50,100,150$, and $250 \mathrm{nM}$ ). Cultures were incubated for 24 and $72 \mathrm{~h}$. Then, $10 \mu 1$ Cell Counting Kit-8 (CCK-8; Dojindo Laboratories, Japan) reagents were added to each well and incubated for an additional $4 \mathrm{~h}$. The absorbance was read at the wavelength of $450 \mathrm{~nm}$ in an automated plate reader. Wells containing the CCK-8 reagents without cells were used as the blank control. Cell proliferation was assessed by the absorbance values according to the manufacturer's protocol.

Apoptosis assay. MSCs were seeded (5x105/well) into 6-well plates. XAT $(50,100,150,200,250 \mathrm{nM})$ induced apoptosis of MSCs was detected by flow cytometry using Annexin V-FITC Apoptosis Detection kit (KGA; KeyGEN Biotechnology) according to the manufacturer's instructions. The apoptosis rate was assayed by using FACSCalibur flow cytometry (Becton Dickinson and Beckman-Coulter, San Jose, CA, USA) at $488 \mathrm{~nm}$.

Chondrogenic differentiation assay and hypertrophic differentiation assay. C3H10T1/2 cells were trypsinized by $0.25 \%$ trypsin and modulated at a density of $10^{5}$ cells $/ \mathrm{ml}$. Two millilitres of the suspension was placed into the center of each well on a 6-well plate (Corning). After incubation for $24 \mathrm{~h}$ at $37^{\circ} \mathrm{C}$ and $5 \% \mathrm{CO}_{2}$, the medium was replaced by $2 \mathrm{ml}$ chondrogenic differentiation medium (Hyclone). The chondrogenic differentiation medium composed of dexamethasone (100 nmol/l), ascorbate $(50 \mu \mathrm{g} / \mathrm{ml})$, ITS supplement, proline $(40 \mu \mathrm{g} / \mathrm{ml})$ and TGF- $\beta 3(10 \mathrm{ng} / \mathrm{ml})$ was replaced every 3 days.

C3H10T1/2 cells were treated by chondrogenic differentiation medium as previously described for 14 days. Then the cells were inducted by hypertrophic differentiation medium composed of dexamethasone $(1 \mathrm{nmol} / \mathrm{l})$, ascorbate $(50 \mu \mathrm{g} / \mathrm{ml})$, ITS supplement, proline (40 $\mu \mathrm{g} / \mathrm{ml})$ and triiodothyronine (T3, $100 \mathrm{ng} / \mathrm{ml}$ ) for another 14 days. Each medium was replaced every 3 days.

Quantitative RT-PCR analysis. Total RNA was isolated using TRIzol reagent (Life Technologies, Carlsbad, NY, USA). Single-stranded cDNA was prepared from $1 \mu \mathrm{g}$ of total RNA using reverse transcriptase with oligo-dT primer according the manufacturer's instructions (Takara, Liaoning, Dalian, China). Two microlitres of each cDNA was subjected to PCR amplification using specific primers with detailed information in Table I. The cycling conditions were set as $95^{\circ} \mathrm{C}$ for $30 \mathrm{sec}, 40$ cycles of $95^{\circ} \mathrm{C}$ for $5 \mathrm{sec}$, and $60^{\circ} \mathrm{C}$ for $30 \mathrm{sec}$ (13). The relative mRNA level was calculated by the normalization to that of GAPDH.

Western blot analysis. The cells were extracted with lysis buffer containing $50 \mathrm{mM}$ Tris ( $\mathrm{pH} 7.6), 150 \mathrm{mM} \mathrm{NaCl}, 1 \%$ Triton X-100, 1\% deoxycholate, $0.1 \%$ SDS, $1 \mathrm{mM}$ PMSF and $0.2 \%$ Aprotinin (Beyotime). After we measured the protein concentration, the equal protein samples were mixed with $5 \mathrm{X}$ sample buffer (Beyotime) and boiled. The proteins $(30 \mu \mathrm{g})$ were resolved by $10 \%$ SDS-PAGE gel and transferred on PVDF membrane (Millipore, Hong Kong, China) by using the semi-dry transfer method. After blocking in $10 \%$ nonfat dried milk in TBST for $2 \mathrm{~h}$, the blots were incubated with primary antibodies including HDAC4 (rabbit polyclonal 1:500, ab12172), p38 (rabbit polyclonal 1:500, ab27986), Runx2 (rabbit polyclonal 1:500, ab23981), Col10a1 (rabbit polyclonal 1:500, ab58632) (all from Abcam), p-p38 (rabbit polyclonal 1:500, bs-50486R), Mmp13 (rabbit polyclonal 1:500, bs-0575R) (both from Bioss) and GAPDH (rabbit polyclonal 1:1,000, ab37168; Abcam) at $4^{\circ} \mathrm{C}$ overnight. After washing by TBST, the blots were incubated with a horseradish peroxidase-conjugated secondary antibody (diluted 1:2,000, sc-2374; Santa Cruz Biotechnology) at room temperature for $1 \mathrm{~h}$. Blots against GAPDH served as loading control.

Glycosaminoglycan (GAG) synthesis analysis by alcian blue staining. To demonstrate the deposition of cartilage matrix proteoglycans, representative cultures were collected at day 28, Then sulfated cartilage glycosaminoglycans (GAGs) were measured by alcian blue (ScienCell) staining. The cells were fixed in $4 \%$ paraformaldehyde for $15 \mathrm{~min}$ and incubated in $3 \%$ acetic aicd for $3 \mathrm{~min}$. Then the cells were stained with 
A<smiles>COc1c2occc2cc2ccc(=O)oc12</smiles>

C

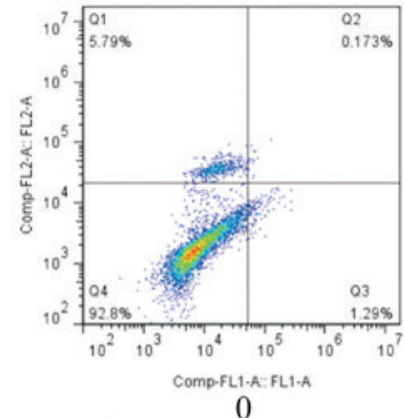

0

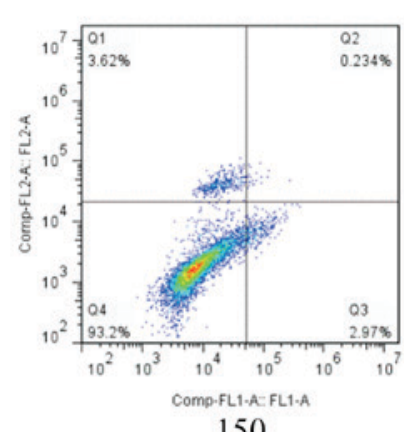

150

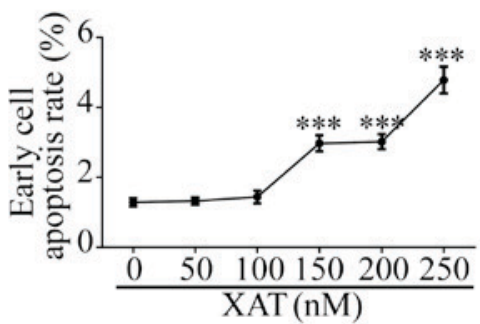

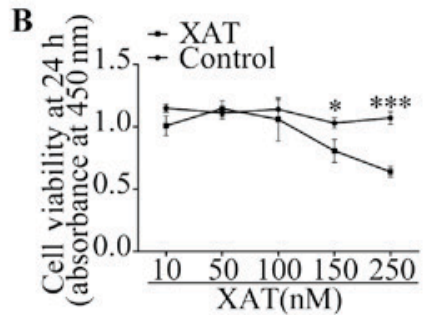
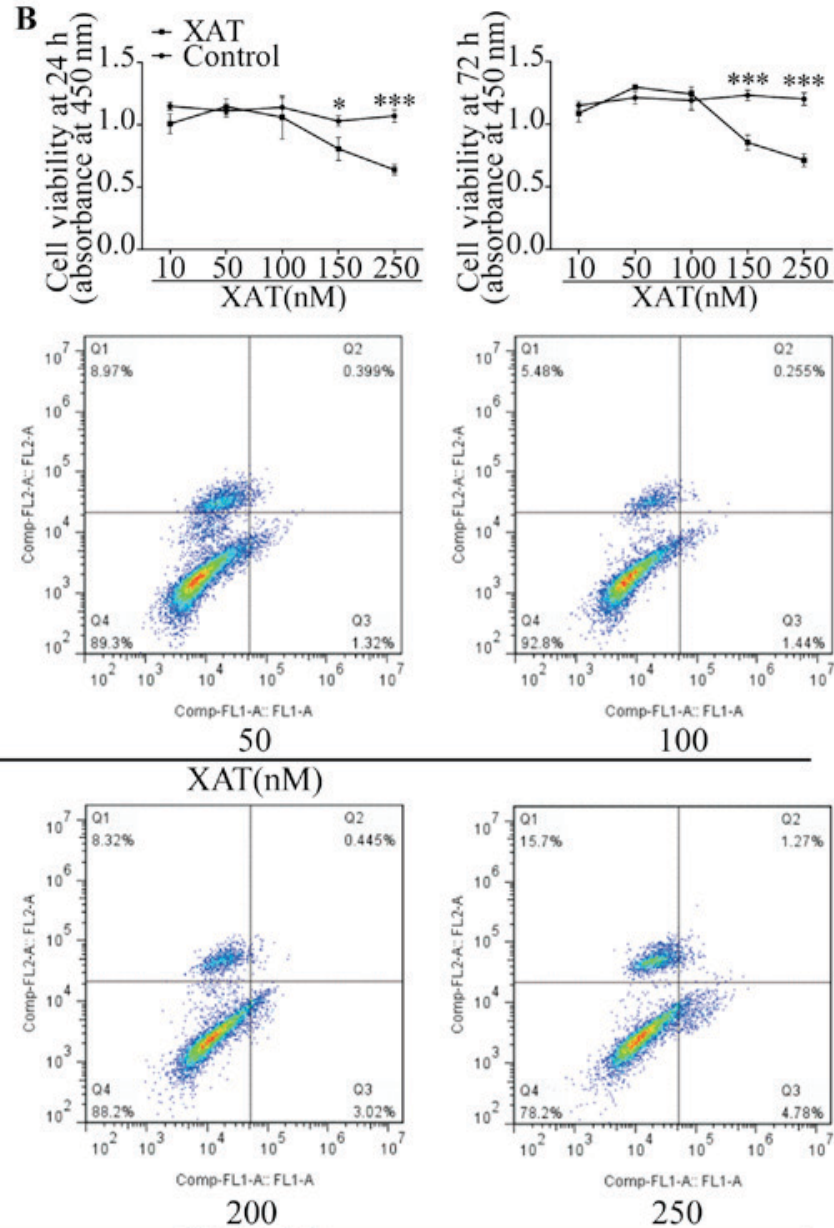

XAT $(\mathrm{nM})$

E

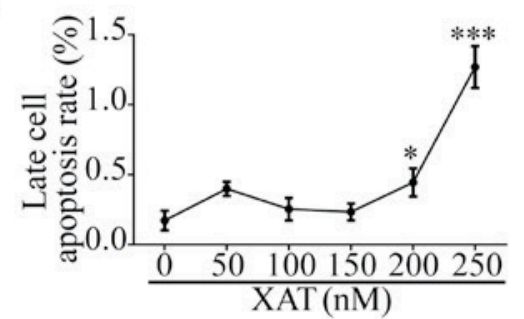

Figure 1. High concentration of XAT inhibited MSCs proliferation and induced early and late stage cell apoptosis of MSCs. (A) Chemical formula of XTA. (B) CCK-8 analysis of cell viability of MSCs treated with different concentrations of XAT for 24 and $72 \mathrm{~h}$. (C) FCM analysis of cell apoptosis rate of MSCs treated with basic medium for $72 \mathrm{~h}$ with different dosages of XAT treatments. X axis represents Annexin V-FITC and Y axis represents propidium iodide. (D) Quantification analysis of early stage cell apoptosis rate. (E) Quantification analysis of late stage cell apoptosis rate. The data in the figures represent the averages \pm SD. Significant differences between the treatment and control groups are indicated in the graph with $\left({ }^{*} \mathrm{P}<0.05\right)$ or $\left({ }^{* * *} \mathrm{P}<0.01\right)$ or $\left({ }^{* * *} \mathrm{P}<0.001\right)$.

alcian blue for $30 \mathrm{~min}$. The mean density was normalized to total cell number.

Immunohistochemistry. The cells were fixed in $4 \%$ paraformaldehyde for $15 \mathrm{~min}$. This was followed by washing in phosphate-buffered saline (PBS) and treated with $\mathrm{H}_{2} \mathrm{O}_{2}$ (ZSGB-BIO, Peking, China) for $10 \mathrm{~min}$ to inactivate endogenous peroxidase. After treatment with normal goat serum (ZSGB-BIO) at room temperature for $15 \mathrm{~min}$, cells were incubated with primary antibodies including Runx2 (rabbit polyclonal 1:150, ab23981) and Col10a1 (rabbit polyclonal 1:150, ab58632) (both from Abcam) at $4^{\circ} \mathrm{C}$ overnight. After washing, the cells were incubated with biotinylated goat anti-rabbit (ZSGB-BIO) secondary antibodies for $30 \mathrm{~min}$, followed by washing and incubation with horseradish peroxidase (HRP) (ZSGB-BIO) for $15 \mathrm{~min}$. The area of the immunocomplex was visualized by chromogen 3,3'-diaminobenzidine (DAB) for $5 \mathrm{~min}$. The cells were investigated under the Olympus microscope. Image-Pro Plus 6.0 software was used to analyze the IOD and area to calculate mean density of images.

Statistics. All data are representative of at least three experiments of similar results performed in triplicate unless otherwise indicated. Data are expressed as mean \pm SEM. One-way ANOVA followed by Student-Newman-Keuls post hoc tests was used to determine the significance of difference between results, with $\mathrm{P}<0.05, \mathrm{P}<0.01$ and $\mathrm{P}<0.001$ being regarded as significant. 
A

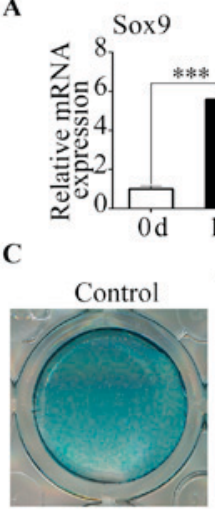

$\mathbf{E}$

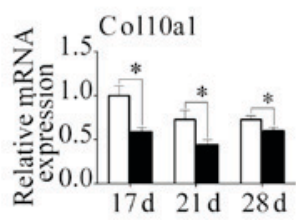

Col2al

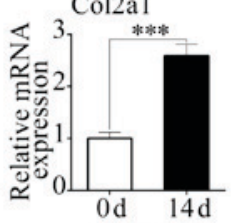

$\mathrm{XAT}(\mathrm{nM})$
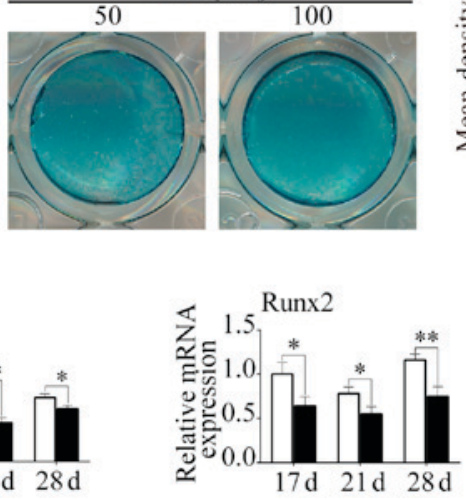

B
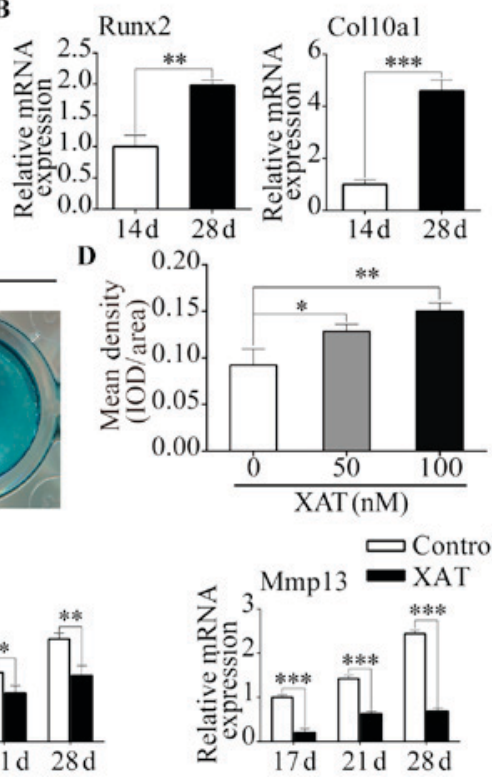

Figure 2. Specific genes expression change during chondrogenic and hypertrophic differentiation. MSCs were induced by chondrogenic medium for 14 days and then treated with hypertrophic medium for another 14 days. (A) Relative mRNA expression levels of Sox 9 and Col2a1 from MSCs in different groups (day 0 and 14). (B) Relative mRNA expression levels of Runx2 and Col10a1 from MSCs in different groups (day 14 and 28). XAT inhibited degradation of glycosaminoglycan and expressions of chondrocyte hypertrophic marker genes on mRNA level. (C) Representative alcian blue staining images of MSCs in different groups (day 28). (D) Quantification of mean intensity of alcian blue staining. (E) Relative mRNA expression levels of Col10a1, Runx2 and Mmp13 from MSCs in different groups (day 17, 21 and 28). The data in the figures represent the averages \pm SD. Significant differences between the treatment and control groups are indicated in the graph with $\left({ }^{*} \mathrm{P}<0.05\right)$ or $\left({ }^{* *} \mathrm{P}<0.01\right)$ or $\left({ }^{* * * *} \mathrm{P}<0.001\right)$.

\section{Results}

Toxicity evaluation of XAT on MSCs. The chemical formula of XAT is shown (Fig. 1A) (14). MSCs were treated with basic medium for $24 \mathrm{~h}$ and $72 \mathrm{~h}$ with different concentrations of XAT followed by CCK- 8 assays (Fig. 1B). The results showed that concentration of XAT higher than $100 \mathrm{nM}$ inhibited proliferation of MSCs $(\mathrm{P}<0.05)$. After culturing MSCs with basic medium for $72 \mathrm{~h}$, we also investigated effect of XAT on cell apoptosis by FCM (Fig. 1C). In the plots, X axis represented Annexin V-FITC and Y axis represented Propidium iodide. The results revealed that XAT concentration above $100 \mathrm{nM}$ affected early cell apoptosis and above $150 \mathrm{nM}$ promoted late cell apoptosis $(\mathrm{P}<0.05$, Fig. 1D and $\mathrm{E})$. Therefore, the safe concentration of XAT used in following experiments was $100 \mathrm{nM}$.

XAT inhibited expression of chondrocyte hypertrophic marker genes. MSCs were treated with chondrogenic differentiation medium containing TGF- $\beta 3(10 \mathrm{ng} / \mathrm{ml})$ for 14 days. RT-PCR was performed to evaluate the expression of chondrogenic genes. The results showed that expressions of Sox 9 and Col2a1 were increased $(\mathrm{P}<0.01)$ on day 14 compared with day 0 (Fig. 2A). Then the cells were induced by hypertrophic medium containing T3 $(5 \mathrm{ng} / \mathrm{ml})$ for another 14 days. Results of RT-PCR revealed that hypertrophic markers including Runx 2 and Col10a1 were increased $(\mathrm{P}<0.01)$ on day 28 compared with day 14 (Fig. 2B). According to this in vitro culture system, we further research the effect of XAT on hypertrophic differentiation of MSCs. After treated with chondrogenic differentiation medium for 14 days without $\mathrm{XAT}$, the cells were induced by hypertrophic medium with
DMSO or with XAT (100 nM) for another 7 and 14 days. From the alcian blue stain, we found that the groups treated with XAT had higher $(\mathrm{P}<0.05)$ intensity than control groups. In addition, the intensity at the concentration of $100 \mathrm{nM}$ was higher $(\mathrm{P}<0.05)$ than $50 \mathrm{nM}$ (Fig. $2 \mathrm{C}$ and $\mathrm{D})$. Besides, after treatment with XAT, expressions of Col10a1, Runx2 and Mmp13 on mRNA level were decreased $(\mathrm{P}<0.05)$ on day 17 , 21 and 28 (Fig. 2E). Results of western blotting revealed that hypertrophic markers including Col10a1, Runx2 and Mmp13 were decreased $(\mathrm{P}<0.05)$ in cells treated with XAT on day 21 and 28 (Fig. 3A and B). We also performed immunohistochemistry to test the effect of XAT on expression of hypertrophic marker genes. The results showed that the mean density of Col10a1 and Runx 2 in groups treated with XAT on day 28 (Fig. 3C and D) were lower $(\mathrm{P}<0.05)$ than those in groups without XAT. Taken together, these results demonstrated that chondrocyte hypertrophic differentiation of MSCs was inhibited by XAT at the concentration of $100 \mathrm{nM}$.

XAT suppressed phosphorylation of p38 and promoted HDAC4 expression during chondrocyte hypertrophic differentiation of MSCs. To explore the molecular mechanisms involved in the effect of XAT on of MSCs, qPCR was performed to test the key transcriptional factors related to chondrocyte hypertrophy. Compared with control groups, we found expression of HDAC4 on mRNA level was increased $(\mathrm{P}<0.01)$ with XAT on day 21 and 28 (Fig. 4A). From the results of western blotting (Fig. 4B), HDAC4 expression was increased $(\mathrm{P}<0.05)$ on day 21 and 28 in the presence of XAT (Fig. 4C). To further illustrate the mechanism of XAT upregulating expression of HDAC4, we next performed western blotting to test the phosphorylation of 


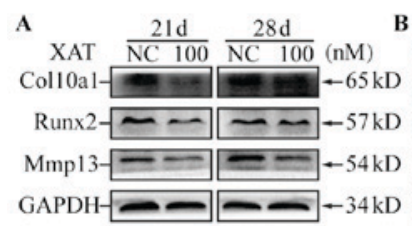

C

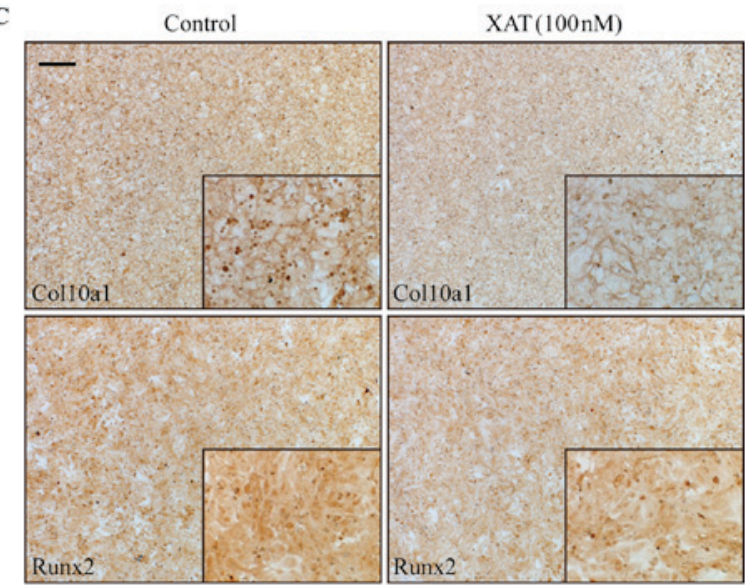

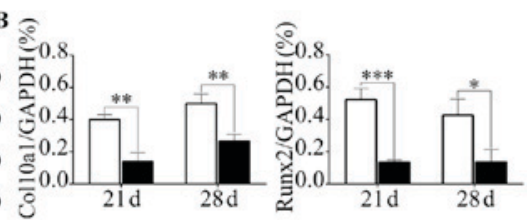

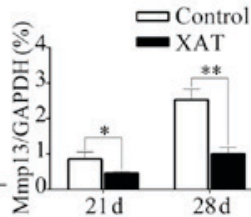

D
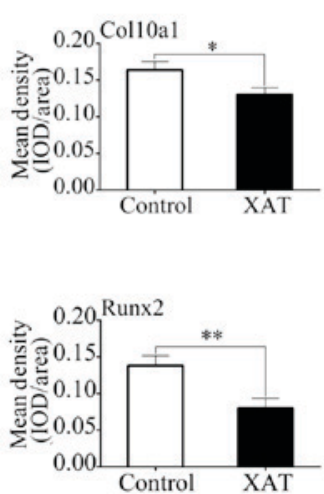

Figure 3. XAT inhibited expressions of chondrocyte hypertrophic marker genes on protein level. MSCs were induced by chondrogenic medium without XAT for 14 days and then treated with hypertrophic medium together with or without XAT for another 3, 7 and 14 days. (A) Representative western blot images of Col10a1, Runx2, Mmp13 and GAPDH from MSCs in different groups (day 21 and 28). (B) Quantification of normalized expression intensity of Col10a1 and Runx2 against GAPDH. (C) Representative immunohistochemical images of Runx2 and Col10a1 from MSCs in different groups (day 28). Scale bar represents $200 \mu \mathrm{m}$. (D) Quantification of mean intensity of Runx2 and Col10a1 in (C). The data in the figures represent the averages \pm SD. Significant differences between the treatment and control groups are indicated in the graph with $\left({ }^{*} \mathrm{P}<0.05\right)$ or $\left({ }^{* * *} \mathrm{P}<0.01\right)$ or $\left({ }^{* * *} \mathrm{P}<0.001\right)$.
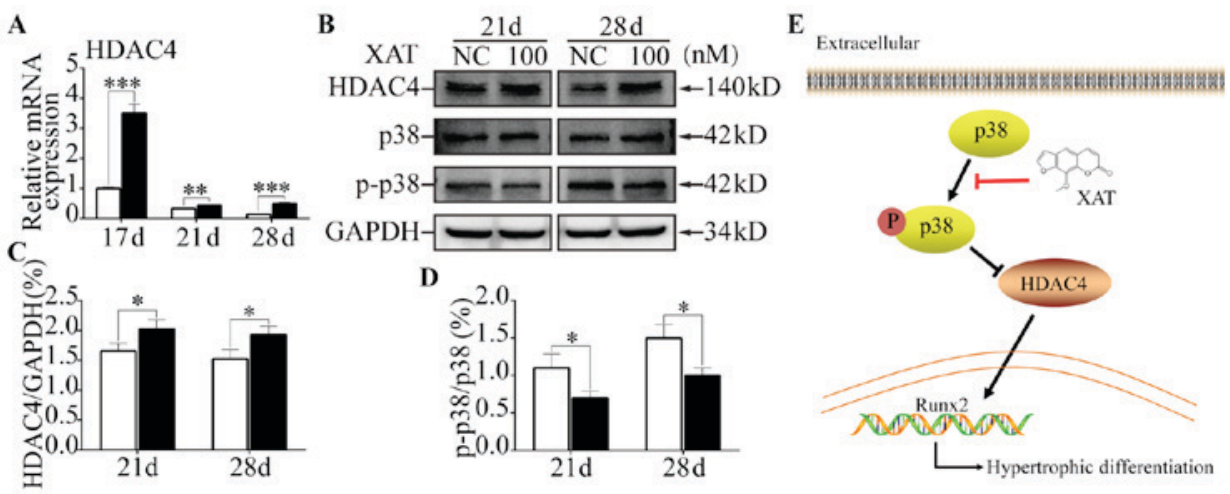

Figure 4. XAT suppressed phosphorylation of p38 and promoted HDAC4 expression during chondrocyte hypertrophic differentiation of MSCs. (A) Relative mRNA expression levels of HDAC4 from MSCs in different groups (day 17, 21 and 28). (B) Representative western blot images of HDAC4, p38, p-p38 and GAPDH from MSCs in different groups (day 21 and 28). (C) Quantification of normalized expression intensity of HDAC4 against GAPDH. (D) Quantification of normalized expression intensity of p38 against p-p38. (E) Schematic diagram of XAT function in chondrocyte hypertrophy. XAT inhibited phosphorylation of $\mathrm{p} 38$ and then promoted expression of HDAC4, ultimately suppressed expression of hypertrophic differentiation gene. The data in the figures represent the averages \pm SD. Significant differences between the treatment and control groups are indicated in the graph with $\left({ }^{*} \mathrm{P}<0.05\right)$ or $\left({ }^{* * *} \mathrm{P}<0.01\right)$ or $\left(^{* * *} \mathrm{P}<0.001\right)$.

p38-MAPK (Fig. 4B). The results revealed that, following XAT treatment, phosphorylation proportion of $\mathrm{p} 38$ was lower $(\mathrm{P}<0.05)$ than control groups on day 21 and 28 (Fig. 4D). Taken together, these results indicated that XAT suppressed phosphorylation of p38 and promoted HDAC4 expression during hypertrophic differentiation of MSCs.

\section{Discussion}

XAT also called Methoxsalen, has various functions, such as anti-inflammatory, analgesic and anti-oxidation (15-17). It is well established that chondrocyte hypertrophy is closely related to inflammation in osteoarticular (18). Based on the characteristics of XAT, we hypothesized that XAT might suppress chondrocyte hypertrophic differentiation of MSCs. A study has found XAT is a new class of anti-glioma drug via evaluating the effect of XAT in MDA-MB-231, CT-26 and SCC-3 cell lines (19). Besides, our group also confirmed that XAT prevents bone loss by inhibiting RANKL-induced osteoclastogenesis (20).

This is the only study to our knowledge to research the role of XAT on chondrocytes. In this study, we provide evidence that XAT could decrease glycosaminoglycan degradation and suppress expressions of chondrocyte hypertrophic 
genes including Runx2, Mmp13 and Col10a1. Then we draw a conclusion that XAT suppresses chondrocyte hypertrophic differentiation of MSCs. The transcription factor Runx2 is crucial for regulating chondrocyte hypertrophy $(21,22)$. Overexpression of Runx 2 in all chondrocytes resulted in premature chondrocyte hypertrophy (23). We screened several upstream genes of Runx 2 to explore the mechanism such as Bapx1, Hoxa2 and HDAC4 through RT-PCR. A recent study showed that Sox 9 directly promoted Bapx 1 gene expression to repress Runx2 in chondrocytes (24). Besides, Hoxa 2 restricted the chondrogenic domain and inhibited bone formation through suppressed Runx 2 expression (25). Studies have found HDAC4, a member of the histone deacetylases, interacts with RUNX2 and decreases RUNX2 binding to DNA. Deletion of HDAC4 greatly promoted chondrocyte hypertrophy while forced expression of HDAC4 in chondrocytes suppressed hypertrophy $(2,26)$. It has been confirmed that HDAC4, which was expressed in prehypertrophic chondrocytes, regulated chondrocyte hypertrophy by interacting with and inhibiting the activity of Runx 2 (27). Besides, a study revealed that HDAC4 inhibited Runx 2 promoter activity in a dosage-dependent manner (28). Therefore, Bapx1, Hoxa2 and HDAC4 might prevent hypertrophy of chondrocytes through reducing RUNX2 activity. Following XAT treatment, Bapx1 and Hoxa 2 expression on mRNA level was not changed (data not shown) while HDAC4 expression was increased on day 21 and 28. The protein level was consistent with RT-PCR. Jun N-terminal kinase (JNK) and p38 mitogen-activated protein kinase (MAPK) signaling is associated with cancers and innate immunity. Inhibition of the p38-MAPK significantly reduced the proliferation and invasion of pancreatic cancer cells under high-glucose conditions (29). Besides, it has been confirmed that neospora caninum increased p38 phosphorylation to downregulate the host's innate immune responses (30). A recent study showed that $\mathrm{p} 38$ promotes HDAC4 degradation by increasing caspase-mediated cleavage (31). Our results showed XAT could increase phosphorylation of p38 in MSCs. So we figured out that XAT inhibited chondrocyte hypertrophy through down-regulating p38-MAPK signaling pathway, then reducing degradation of HDAC4 (Fig. 4E).

In OA, chondrocytes exhibit hypertrophic morphology and the homeostasis of chondrocyte is broken down. Hhpertrophic chondrocytes express crucial transcription factor Runx2 and secrete Mmp13, which leads to degradation of extracellular matrix (32). Then the function of articular cartilage is severely impaired. Moreover, regenerated cartilage which is constructed by tissue engineering always presents fibrocartilage but hyaline cartilage. Chondrocyte hypertrophic differentiation is the root to cause above phenomenon (33). Hence, inhibition of chondrocyte hypertrophy is the key point to treat arthritis and maintain the function of regenerated cartilage.

XAT, from the common spices, could suppress expressions of chondrocyte hypertrophic genes by inactivating p38-MAPK/HDAC4 signaling pathway. The above data indicate that XAT can be used as a potential drug for the treatment of arthritis and also for maintaining the homeostasis of regenerated cartilage in construction of tissue engineered cartilage.

\section{Acknowledgements}

This work was funded by grants from the Nature Science Foundation of China (no. 81571893 and 81271980), the National High-Tech R\&D Program of China (863 Program, 2015AA020315) and the Key Project of Logistics Research Plan of PLA (BWS13C014).

\section{References}

1. Hinton RJ, Jing Y, Jing J and Feng JQ: Roles of chondrocytes in endochondral bone formation and fracture repair. J Dent Res 96: 23-30, 2017.

2. Long F and Ornitz DM: Development of the endochondral skeleton. Cold Spring Harb Perspect Biol 5: a008334, 2013.

3. Cancedda R, Castagnola P, Cancedda FD, Dozin B and Quarto R: Developmental control of chondrogenesis and osteogenesis. Int J Dev Biol 44: 707-714, 2000.

4. Glyn-Jones S, Palmer AJ, Agricola R, Price AJ, Vincent TL, Weinans H and Carr AJ: Osteoarthritis. Lancet 386: 376-387, 2015.

5. Bianchi A, Guibert M, Cailotto F, Gasser A, Presle N, Mainard D, Netter P, Kempf H, Jouzeau JY and Reboul P: Fibroblast growth factor 23 drives MMP13 expression in human osteoarthritic chondrocytes in a Klotho-independent manner. Osteoarthritis Cartilage 24: 1961-1969, 2016.

6. Wang T, Lai JH and Yang F: Effects of hydrogel stiffness and extracellular compositions on modulating cartilage regeneration by mixed populations of stem cells and chondrocytes in vivo. Tissue Eng Part A 22: 1348-1356, 2016.

7. Di Luca A, Szlazak K, Lorenzo-Moldero I, Ghebes CA, Lepedda A, Swieszkowski W, Van Blitterswijk C and Moroni L: Influencing chondrogenic differentiation of human mesenchymal stromal cells in scaffolds displaying a structural gradient in pore size. Acta Biomater 36: 210-219, 2016.

8. Garg BJ, Garg NK, Beg S, Singh B and Katare OP: Nanosized ethosomes-based hydrogel formulations of methoxsalen for enhanced topical delivery against vitiligo: Formulation optimization, in vitro evaluation and preclinical assessment. J Drug Target 24: 233-246, 2016.

9. Archier E, Devaux S, Castela E, Gallini A, Aubin F, Le Maître M, Aractingi S, Bachelez H, Cribier B, Joly P, et al: Carcinogenic risks of psoralen UV-A therapy and narrowband UV-B therapy in chronic plaque psoriasis: A systematic literature review. J Eur Acad Dermatol Venereol 26 (Suppl 3): S22-S31, 2012.

10. Yang H, Xiong J, Luo W, Yang J and Xi T: 8-Methoxypsoralen induces intrinsic apoptosis in HepG2 cells: Involvement of reactive oxygen species generation and ERK1/2 pathway inhibition. Cell Physiol Biochem 37: 361-374, 2015.

11. Panno ML, Giordano F, Palma MG, Bartella V, Rago V, Maggiolini M, Sisci D, Lanzino M, De Amicis F and Andò S: Evidence that bergapten, independently of its photoactivation, enhances p53 gene expression and induces apoptosis in human breast cancer cells. Curr Cancer Drug Targets 9: 469-481, 2009.

12. Zagaja M, Andres-Mach M, Patrzylas P, Pyrka D, Szpringer M, Florek-Łuszczki M, Źółkowska D, Skalicka-Woźniak K and Łuszczki JJ: Influence of xanthotoxin (8-methoxypsoralen) on the anticonvulsant activity of various novel antiepileptic drugs against maximal electroshock-induced seizures in mice. Fitoterapia 115: 86-91, 2016.

13. Livak KJ and Schmittgen TD: Analysis of relative gene expression data using real-time quantitative PCR and the 2(-Delta Delta C(T)) method. Methods 25: 402-408, 2001.

14. Tian W, Cai J, Xu Y, Luo X, Zhang J, Zhang Z, Zhang Q, Wang X, Hu L and Lin G: Determination of xanthotoxin using a liquid chromatography-mass spectrometry and its application to pharmacokinetics and tissue distribution model in rat. Int $\mathrm{J}$ Clin Exp Med 8: 15164-15172, 2015.

15. Wolnicka-Glubisz A, Sarna T, Klosner G, Knobler R and Trautinger F: UVA activated 8-MOP and chlorpromazine inhibit release of TNF-alpha by post-transcriptional regulation. Photochem Photobiol Sci 3: 334-336, 2004.

16. Chen YF, Tsai HY and Wu TS: Anti-inflammatory and analgesic activities from roots of Angelica pubescens. Planta Med 61: 2-8, 1995. 
17. Ng TB, Liu F and Wang ZT: Antioxidative activity of natural products from plants. Life Sci 66: 709-723, 2000.

18. Caron MMJ, Emans PJ, Surtel DA, van der Kraan PM, van Rhijn LW and Welting TJ: BAPX-1/NKX-3.2 acts as a chondrocyte hypertrophy molecular switch in osteoarthritis. Arthritis Rheumatol 67: 2944-2956, 2015.

19. de Oliveira DM, Ferreira Lima RM, Clarencio J, Velozo Eda S, de Amorim IA, Andrade da Mota TH, Costa SL, Silva FP and El-Bachá Rdos S: The classical photoactivated drug 8-methoxypsoralen and related compounds are effective without UV light irradiation against glioma cells. Neurochem Int 99: 33-41, 2016.

20. Dou C, Chen Y, Ding N, Li N, Jiang H, Zhao C, Kang F, Cao Z, Quan H, Luo F, et al: Xanthotoxin prevents bone loss in ovariectomized mice through the inhibition of RANKL-induced osteoclastogenesis. Osteoporosis Int 27: 2335-2344, 2016.

21. Liu CF, Samsa WE, Zhou G and Lefebvre V: Transcriptional control of chondrocyte specification and differentiation. Semin Cell Dev Biol 62: 34-49, 2017

22. Guo F, Han X, Wu Z, Cheng Z, Hu Q, Zhao Y, Wang Y and Liu C: ATF6a, a Runx2-activable transcription factor, is a new regulator of chondrocyte hypertrophy. J Cell Sci 129: 717-728, 2016.

23. Takeda S, Bonnamy JP, Owen MJ, Ducy P and Karsenty G: Continuous expression of Cbfa1 in nonhypertrophic chondrocytes uncovers its ability to induce hypertrophic chondrocyte differentiation and partially rescues Cbfal-deficient mice. Genes Dev 15: 467-481, 2001.

24. Yamashita S, Andoh M, Ueno-Kudoh H, Sato T, Miyaki S and Asahara H: Sox9 directly promotes Bapx1 gene expression to repress Runx2 in chondrocytes. Exp Cell Res 315: 2231-2240, 2009.

25. Kanzler B, Kuschert SJ, Liu YH and Mallo M: Hoxa-2 restricts the chondrogenic domain and inhibits bone formation during development of the branchial area. Development 125: 2587-2597, 1998.
26. Chen W, Sheng P, Huang Z, Meng F, Kang Y, Huang G, Zhang Z, Liao W and Zhang Z: MicroRNA-381 regulates chondrocyte hypertrophy by inhibiting histone deacetylase 4 expression. Int J Mol Sci 17: E1377, 2016.

27. Vega RB, Matsuda K, Oh J, Barbosa AC, Yang X, Meadows E, McAnally J, Pomajzl C, Shelton JM, Richardson JA, et al: Histone deacetylase 4 controls chondrocyte hypertrophy during skeletogenesis. Cell 119: 555-566, 2004.

28. Li P, Wei X, Guan Y, Chen Q, Zhao T, Sun C and Wei L: MicroRNA-1 regulates chondrocyte phenotype by repressing histone deacetylase 4 during growth plate development. FASEB J 28: 3930-3941, 2014.

29. Wang L, Bai YY, Yang Y, Hu F, Wang Y, Yu Z, Cheng Z and Zhou J: Diabetes mellitus stimulates pancreatic cancer growth and epithelial-mesenchymal transition-mediated metastasis via a p38 MAPK pathway. Oncotarget 7: 38539-38550, 2016.

30. Mota CM, Oliveira AC, Davoli-Ferreira M, Silva MV, Santiago FM, Nadipuram SM, Vashisht AA, Wohlschlegel JA, Bradley PJ, Silva JS, et al: Neospora caninum activates p38 MAPK as an evasion mechanism against innate immunity. Front Microbiol 7: 1456, 2016.

31. Zhou JM, Li PC, Chen Q, Wei X, Zhao T, Wang Z and Wei L: Mitogen-activated protein kinase p38 induces HDAC4 degradation in hypertrophic chondrocytes. Biochim Biophys Acta 1853 370-376, 2015.

32. Kung LH, Zaki S, Ravi V, Rowley L, Smith MM, Bell KM, Bateman JF and Little CB: Utility of circulating serum miRNAs as biomarkers of early cartilage degeneration in animal models of post-traumatic osteoarthritis and inflammatory arthritis. Osteoarthritis Cartilage 25: 426-434, 2017.

33. Doran PM: Cartilage tissue engineering: What have we learned in practice? Methods Mol Biol 1340: 3-21, 2015. 